\title{
Review on Theorizing Yoga and Dance/Movement Therapy as a Mindfulness Skill
}

\author{
Mehrnaz Dehghan ${ }^{1 *}$
}

\section{ABSTRACT}

The aim associated with this is to theorizing to the developing example of therapists educated in both of the dance/movement therapy (DMT) and yoga and also to give information regarding the combination of DMT and yoga and practitioners' perceptions of how this might influence their routines mindfulness. Yoga, dance movement therapy, and mindfulness intention to accomplish the same aim of quieting the mind and requiring participants seek inside. Within this article, yoga principles are described because of their possibilities aspect in mindfulness skill progress as well as DMT. A consideration of the literature presents a description of yoga, DMT and additionally the theory of mindfulness, which includes relieves negative performing and boost of mental well-being, actual physical well-being, and behavior maintenance. The procedure during which yoga is theorized to operate as a mindfulness skill discussed alongside future guidelines for theoretical development. Because of both DMT and yoga really are mind-body methods that show positive psychotherapeutic usefulness patients undergoing treatment with them concurrently, this might be the inspiration for so many DMTs to be given learning yoga as well by using mindfulness techniques. The particular sections the perfect two modalities complement one another are, briefly, as shown below: both address the undeniable fact that emotions are handled in practice; they actually focus on the subject of understanding the body/body awareness, observation techniques, and more than that anatomy; DMT discusses to the concern about verbalizing the psychological process; and yoga offers a pattern of self-care regarding the therapist along with a method to take more people into the movement practical experience and produce to the mindfulness as powerful tools.

Keywords: Yoga, Dance /Movement Therapy, Mindfulness

The various different incarnations of psychoanalysis and psychotherapy represent effective in minimizing suffering, especially if the body and its resources are part of the treatment [1]. Mindfulness is currently a necessary feature of many fields of life from school, home, work, and play. And in addition, the latest progressions in neuroscience and brain plasticity have brought

\footnotetext{
${ }^{1}$ Research Scholar, Department of Psychology, Aligarh Muslim University, Aligarh-202002 (U.P), India *Responding Author

(c) 2016 I M Dehghan; licensee IJIP. This is an Open Access Research distributed under the terms of the Creative Commons Attribution License (http://creativecommons.org/licenses/by/2.0), which permits unrestricted use, distribution, and reproduction in any Medium, provided the original work is properly cited.
} 


\section{Review on Theorizing Yoga and Dance/Movement Therapy as a Mindfulness Skill}

revolutionary operate in the use of mindfulness in the relief for anxiety, depression, emotional dysregulation, anger, stress along with other mental well-being cases [2]. Mindfulness within its modern non-religious technique that typically has been well known as "the awareness that is apparent through paying attention on purpose, in the present moment, and non-judgmentally to the relating of experience"[3]. Using guided meditation just like a procedure of creating comfort within the body assisted in reaching the goal of enhancing one's awareness of emotions, thoughts and sensations by using of body-based methods [4]. It should be noted that great body of studies exists on yoga and its healing properties, it has only recently benefitted from empirically based studies that highlight clinical research outcomes involving the effects of yoga on mental wellbeing client populations. Such studies include Khumar [5].Hatha yogis, we felt, would have taken advantage of dropping into stillness and harmony for longer stretches of time and paying attention to the developing and passing away from moment to moment of mind/body skills in one sitting pose [6]. An essential perception of DMT is that emotions manifest in the sensations and energies of the body and are of equal significance to the inception of and awareness of one's cognitive processes [7].Therefore, a typical treatment goal in DMT is to increase a client's body awareness with the purpose of increasing emotional self-awareness [8]. Improving a mind-body interconnection presents a full awareness of and communication with one's self through increased consciousness of needs in treatment to increase insight, prevent relapse, and promote general health through improved self-regulation [9]. Though yoga, DMT, and mindfulness share similar goals, little research exists connecting body based therapeutic techniques, that include DMT, and mindfulness cognitive techniques. Just one thesis has been written evaluating a yoga and DMT program, based on mindfulness, with persons managing symptoms of chronic mental illness [10].

Reflecting the lack of overlap in the available literature, this literature review has been divided into five sections.

The first goal is to define and characterize yoga, by primarily drawing upon yogic texts and the developing scholarship on the topic. Many readers may find the concept of yoga unfamiliar or resist participation due to Western misconceptions surrounding the now popularized physical practice of yoga. The second goal is to place mindfulness in the context of therapeutic skills training for mental health professionals and to expose a process through which yoga is theorized as a mindfulness skill. The third define and characterize dance /movement therapy, The fourth goal is to place mindfulness in the context of therapeutic skills training for mental health professionals and to expose a process through which DMT is theorized as a mindfulness skill.

The paper concludes with the fifth goal of proposing future directions in theoretical development and an operational definition of yoga and DMT as mindfulness skill.

\section{ORIGINS OF YOGA}

"YOGA" definitely is an ancient Sanskrit word which, in only two syllables, involves the whole body of spiritual experiences and experiments of tens of thousands of Knew Masters [11].Yoga 
is moreover closely related to the spiritual opinions and principles of the other Indian religions [12].The word "Yoga" is mostly identified as "union". It implies that the individual is unified with the Universe, the individuality with the Universality. This means "to join together". Actually "One might more efficiently say Yoga is "reunion". The Upanishad mentions, "That which was one became the many." The knowledge of Yoga increases the "return of the many to the One"[11].Yoga's extended wealthy background can be divided up into four major durations of innovation, practice, and development. The beginning of Yoga was exposed through IndusSarasvati civilization in Northern India far over 5,000 in years past. The Upanishads achieved the idea of tradition sacrifice from the Vedas and internalized it, guiding the sacrifice of the ego through self-knowledge, act (karma yoga) and wisdom (jnana yoga) [13]. One of the original written content having to do with Yoga was compiled in India by a scholar named Patanjali, who set down the most widespread Yoga approach and practices of his time in a book he titled Yoga Sutras ("Yoga Aphorisms") as soon as the 1st or 2nd century B.C. or maybe as late as the 5th century A.D. The procedure which he wrote about is coined "Ashtanga Yoga," or the eight limbs of Yoga, and that is what is basically named Classical Yoga [14]. A few centuries after Patanjali, yoga gurus created a structure of practices created to rejuvenating the entire body and expand life span. This exploration of these physical-spiritual connections and body-centered practices concluded in the creation of all that we usually consider that of yoga in the western world: Hatha Yoga [15]. While the philosophy continues fairly consistent between different disciplines the physical feature of yoga is supplied in a few types.

Table 1: Distinguishing features of various forms of yoga.

\begin{tabular}{|l|l|}
\hline $\begin{array}{l}\text { Types } \\
\text { yoga }\end{array}$ & Personality or concept \\
\hline Ashtanga & a strenuous series of poses sometimes referred to as power yoga. \\
\hline Hatha & $\begin{array}{l}\text { Postures are held for minutes, this is believed to really affect the body, as each } \\
\text { posture is designed to gain health benefits. The longer you hold the pose, the } \\
\text { more effective it is. }\end{array}$ \\
\hline $\begin{array}{l}\text { Vinyasa/ } \\
\text { Anusara }\end{array}$ & $\begin{array}{l}\text { A gentle type of yoga, well suited for those just starting out, or for those who'd } \\
\text { like to go at a slower pace. Slow free-flowing movements between poses. }\end{array}$ \\
\hline Kundalini & $\begin{array}{l}\text { This school of thought believes that nerve centers in the body can get clogged up } \\
\text { or inactive and this leads to poor health. Kundalini's repetitive posture flows } \\
\text { (kriyas) unlock these blocks and leave you feeling wonderfully energized yet } \\
\text { peaceful. }\end{array}$ \\
\hline Bikram & Yoga practiced in a high temperature room. \\
\hline $\begin{array}{l}\text { Iyengar } \\
\text { Yoga }\end{array}$ & $\begin{array}{l}\text { (Prop yoga) created by a yoga master named Iyengar in India, this type of yoga is } \\
\text { very therapeutic. You are placed into positions with various props (blocks, straps, } \\
\text { chairs). }\end{array}$ \\
\hline
\end{tabular}




\section{THE PRACTICE OF YOGA}

Although there are numerous varieties of yoga practices, yoga typically combines stretching exercises and different postures with deep breathing and meditation. Yoga is created to stretch and shape the muscles and in addition to keeping the spinal column and joints flexible[16]. Yoga is generally practiced in unattached clothing and unfilled feet on a mat. Staying focused on each single movement on the deep abdominal breathing that is connected with each movement and typically the postures are kept for 4 to 5 breaths regarding the different coaching kinds of yoga which get popular today including Hatha, Ashtanga, Anasara, Iyengar and Bikram[17]. the practice of yoga is most often accompanied with the most extensively subscribed yoga discipline, Hatha Yoga[18]. Regarded classical yoga, Hatha is a yoga technique that goes back to ancient India however it has developed from its original traditions and now produces many postures (yoga poses) incorporated with deep breathing.Hatha Yoga is extremely regarded in the yoga community: according to yogis, Hatha-yoga creates a state of well-being and stillness of the $\operatorname{mind}[19]$.

\section{YOGA IN CLINICAL RESEARCH}

There's been a number of studies directly into advantages and benefits of Indian-based yoga in healthy populations and medical populations. Early texts described yoga's physical and psychological health benefits [20]. Since 2005, interest has continued to grow to invalidate the health rewards of yoga through clinical research. It is outside limits purview of this paper to completely investigate the research literature on this subject; however, several comprehensive reviews of clinical research exist [5]. One particular review realized that yoga provided the improvement in areas such as anxiety, depression, sleep worries, low back ache, headaches, hypertension, and stress. Furthermore, the physiological results of yoga such as decreased heart beating rate and blood pressure and the physical effects including weight reduction and increased muscle strength are reviewed [17]. Other reviews such as Kelly B. Smith_ and Caroline F. Pukall(2008) An evidence-based review article of Yoga as a complementary therapy for participants by having cancer, [21] Raub s (2002) classic literature review of Hatha Yoga[22], review all offer considerable understanding of other recent studies exploring the capability of yoga.

\section{CLINICAL APPLICATION OF MINDFULNESS}

Utilization of mindfulness meditation as a kind of behavioral therapy to treat medical problems set out with the work of Jon Kabat-Zinn, which actually searched the application of mindfulness meditation in curing clientele along with chronic pain (Kabat- Zinn, 1982), now well known popularly as Mindfulness-Based Stress Reduction. While in the time of establishment of MBSR, several other procedures have often been developed using mindfulness-related principles and routines, including [23]. Mindfulness has its origins in centuries-old traditions, yet is now served in standardized mindfulness training methodologies (ST-Mindfulness)1" Inclusive of mindfulness-based stress reduction (MBSR) and mindfulness-based cognitive therapy (MBCT)[24][25].Moreover, one outstanding question is connected to which specific ingredients of this multifaceted intervention are promoting the observed benefits[26]. Most ST-Mindfulness practices need some certain degree of endurance in the capability to remain stationary for an 


\section{Review on Theorizing Yoga and Dance/Movement Therapy as a Mindfulness Skill}

extended period, sometimes nearly $45 \mathrm{~min}$. This can be difficult for people who find it difficult to remain seated and focused. Many of the groups who may therefore take pleasure in training based on mindful movement include: (i) those for whom the composition and quality of mental experience is chaotic, disorganized, and distressing (e.g., visual or auditory hallucinations, paranoid delusions, racing thoughts and suicidal ideation, depersonalization); (ii) those whose illness could have compromised their attention capabilities; (iii) those whose neurological or developmental disabilities create the metacognitive aspects of the workout challenging; (iv) those for whom abnormalities (typically over-activity) in the motor system from section of the pathology of the disorder (for example ADHD, Tics, Tourette etc.); and (v) any others who find it difficult to sit still for a relatively long period of time[26]

Table2: types of mindfulness and clinical application of each technique

\begin{tabular}{|c|c|}
\hline \begin{tabular}{|lr|}
\multicolumn{2}{|l}{ Mindfulness-Based } \\
Stress & Reduction \\
(MBSR) &
\end{tabular} & Chronic pain and stress-related disorders (Kabat-Zinn et al., 1992)[27] . \\
\hline $\begin{array}{l}\text { Mindfulness-Based } \\
\text { Cognitive Therapy } \\
\text { (MBCT) }\end{array}$ & A treatment for chronic depression (Kabat-Zinn et al., 1992)[28]. \\
\hline $\begin{array}{l}\text { Dialectical Behavior } \\
\text { Therapy }\end{array}$ & $\begin{array}{l}\text { Developed by Martha Linehan for use with people with borderline } \\
\text { personality disorder[29]. }\end{array}$ \\
\hline $\begin{array}{l}\text { Acceptance and } \\
\text { Commitment Therapy }\end{array}$ & $\begin{array}{l}\text { Developed by Steven Hayes, Kelly Wilson, and Kirk Strosahl to } \\
\text { increase psychological flexibility[30]. }\end{array}$ \\
\hline $\begin{array}{l}\text { Mindfulness-Based } \\
\text { Relapse Prevention }\end{array}$ & $\begin{array}{l}\text { Developed by Alan Marlatt individuals in addictive behavior recovery } \\
\text { for substance-abuse relapse prevention[31]. }\end{array}$ \\
\hline $\begin{array}{l}\text { Mindfulness- Based } \\
\text { Eating Awareness } \\
\text { Training(MB-EAT) }\end{array}$ & Developed by Jean Kristeller for binge-eating disorders[32]. \\
\hline $\begin{array}{l}\text { Mindfulness-Based } \\
\text { Childbirth and } \\
\text { Parenting(MBCP) }\end{array}$ & $\begin{array}{l}\text { Developed by Larissa Duncan for pregnant women to promote family } \\
\text { health and well-being through the practice of mindfulness during } \\
\text { pregnancy, childbirth, and early parenting[33] }\end{array}$ \\
\hline
\end{tabular}

Clinical applications including MBSR and MBCT have standardized approaches, that is, the techniques could have been described completely in manuals and are relatively invariant wherever, whenever, and by whoever are taught[34].Employ formal and informal practice in mindfulness meditation, education, discussions, and intensive home practice. Mindfulness meditation practice incorporates mindful focus to body sensations, mindful breathing, sitting meditations, Hatha yoga, and daily routines. Informal mindfulness practices are applied to any activity, like walking, cooking, and eating [28].

\section{THEORIZING YOGA AS A MINDFULNESS SKILL}

Yoga can be one of the six orthodox Indian philosophies, providing the practical methodological pathway toward attainment of "self-realization”[35].Which is certainly conceptualized as housed 


\section{Review on Theorizing Yoga and Dance/Movement Therapy as a Mindfulness Skill}

in a state of universal consciousness when experiencing the higher "Self "(Feuerstein, 1998)[36]. Yogic philosophy in like method describes a three-stage process where this quietness of the mind is achieved In the primary stage, a yoga practitioner, similarly to mindfulness, focuses their attention. In the second stage, a yoga practitioner turns focusing inwards on themselves. Mindfulness identifies this just like an awareness of what essentially occurs to us and is us at the successive moments of perception. The third stage in yoga is full participation [5]. A significant element of many mindfulness-based operations is mindful movement, such as the practice of yoga [37].Hatha yoga specifically is based body-mind-breath harmony in a mindful approach, gradually working on physical and mental strength, flexibility, and balance. The focus is on the release of physical, mental, and emotional tension[38].In keeping with this conceptualization, the current discussion proceeds with the understanding that yoga is an integration of three interrelated components, asanas (physical postures), pranayama (focused breathing), and dhyana (meditation)[38][39].

The following section will describe each of these elements and the purported associated benefits. Asana When practiced in combination with proper breathing and concentration, the postures of yoga are a vehicle for self-awareness[40]. As the knowledge of the body grows through regular practice, the practitioner learns to collaborate with the body to enjoy the fluidity of movement in entering, holding, and leaving the postures. The emphasis during asana practice is noncompetitive and the individual is encouraged to become aware of internal sensations thoughtfully and mindfully. In this manner, individual growth is progressive over time to create a balanced integration of the mind, body, and spirit[28].

Pranayama the breath is an essential feature of yoga.the quality of the breath determines the quality of life. Although breathing is an automatic function, the ability to consciously control aspects of breathing can greatly affect the nervous system. During the practice of yoga, the breath is used to calm the nervous system, which in turn serves to calm the mind[41]. In general, during yoga practice, contractions of the body are associated with exhalation, and expansions of the body are facilitated by inhalations.

Dhyana As mentioned previously in this section, yoga is a journey toward self-awareness. Yoga is a meditative process with the ultimate goal of focusing the energies of the mind and body to create a sense of inner peace. During the practice, the yoga practitioner learns to observe internal and external events without judgment and/or evaluation it has been argued that the postures, breathing, and relaxation techniques practiced in yoga, work together toward the goal of meditation. In this context, meditation involves mindfulness, which involves the act of compassionate observing of the body, nervous system, and mind, and focused attention. These aspects work together to create a clear, one-pointed mind [42]. Yoga and mindfulness were combined within the Mindfulness-Based Stress-Reduction (MBSR) programmed[6].The aim is certainly not to perfect postures, but instead of finding out with every breath external and internal stimuli and experiences in the present moment with truthfulness, curiosity and without ever 
having judgment. Movement by itself though has a promoting effect, causing increased awareness and consciousness. Mindful involvement in yogic practice improves one's ability to make note of stimuli, notice bodily sensations and release emotional tension. Basically, mindful yoga is not only physical activity, rather a personal practice which will provide development of concentration to the present moment, therewith deepening self-awareness [43][44].

A key training element is repeatedly progressing to physical information from the body. All of this is done over a number of practices, that can be none moving (e.g., supine body scan) or moving (e.g., slow mindful walking, stretching, and yoga). The mindful movement practices would have a certain capability evidenced due to discovering that mindful yoga, although completed for the quickest time period in comparison with other practices, had the foremost significant effect on modifications in mindfulness, well-being, and medical symptoms [45]

\section{DEFINITION AND PRINCIPLE OF DANCE/MOVEMENT}

Therapy Dance/movement therapy is defined as, "the psychotherapeutic using of movement just like a process which furthers the emotional, cognitive, social and physical integration of the individual” (American Dance Therapy Association 2007). It is founded on the principal that the mind and body are intricately connected and also that any, "change in one of these domains produces corollary change in the other" [46][47].Schmais (1974) defined four basic characteristics of DMT. In summary they are as shown below: DMT is expressive of emotions; DMT is developmental; DMT is physically integrative; and DMT is inclusive, in other words, it may be utilized with anyone [10]. The exercises were designed to unify the actions of breathing, muscular fluctuation, and feeling. From each of these exercises she, "encouraged her patients to develop a personal sensitivity to their body processes by getting them do movement sequences that organically supported and facilitated the integration of the emotional and physical experiences of the self” [8]. Through body action, the DMT work to assist the patient creates a realistic body image and also to activate and integrate body parts during movement sessions. The DMT guides patients in becoming more aware of inner sensations in order to develop with additional control over his/her body movements. Another goal with regard to body action includes mobilizing energy within the body [10].Dance/movement therapists also work with the concepts of grounding, connectivity in the body, breath support, and organization of the body. These elements are included in the twelve principles of the Bartenieff Fundamentals. The principles are defined as the initial truths which supply central support regarding the Bartenieff Fundamentals [48] [49].The first principle is total body connectivity. This is basically the concept that the entire body is connected so that change in a single part changes the whole body as a whole. The second principle is breath support. Target the breath is important in movement and body studies. When movement is supported by breath, the movement can happen with more fluidity. Breath influences every aspect of the movement. The third principle is grounding. Whenever one is "grounded" it implies that one is stable in each of a mental and physical sense. Dance/movement therapists often promote grounding within the DMT session. They invite their patients for being aware of the connection their bodies have with the earth and to let their weight 


\section{Review on Theorizing Yoga and Dance/Movement Therapy as a Mindfulness Skill}

sink into the provide support for the earth is offering. By becoming more connected with the earth, "movement can then journey through the body utilizing that sense of grounded stability as a base by which to move"[50].The intent is another important principle that defines elements with which dance/movement therapists' work. The process the patient moves is based on their inner intent in four areas: Body, Effort, Shape, and Space. A body-level intent, "might include clarifying wherein the body movement initiates and the way the movement sequences through the body parts to complete the phrase".Effort intent, "might include being in or revealing an inner mood, a feeling, or making a dynamic statement in movement”[51]. The intent in Shape could include forming the body to facilitate relationships with others or the environment, or to form a particular shape with the body. The last area in which intent may be shown is space intent in space might be to go in a particular direction or in a particular form. Spatial desire "organizes and clarifies body connections by establishing a clear pathway/goal for the movement”[52].

\section{CLINICAL APPLICATION OF DANCE/MOVEMENT THERAPY}

In order to figure out the clients as well as to consider the processes and benefits of DMT work, DMT is an investigation informed practice. As well - research is also attempted to further the identification of the profession through the distribution of the research findings in conferences, publications and also on daily discussions with general society, clients as well as doctors and other members of the multi-disciplinary team in medical, social care or educational setting. Research in DMT may include the variety of topics, and methodologies include qualitative and quantitative as well as mixed approaches.

\section{DMT in psychiatry}

\section{Emotional eating}

Research led by Bonnie Meekums and conducted in Latvia 8 explored the impact of DMT in obese women with emotional eating who were trying to reduce weight. Revelation the DMT group indicated statistically lowered psychological distress, decreased body image distress, and raised self-esteem in comparison with controls. Emotional eating cut down in DMT and training groups [53]

\section{Depression}

A study conducted in Finland investigates using the body and movement-based therapy intervention among the treatment for depression. Central to this particular study is using a shortterm group type of DMT intervention that had a positive effect on patients with depression [54].A study12 assessed the profiles of psychological well-being and changes in neurohormones of adolescents with mild depression after approximately 3 months of DMT. Plasma serotonin quantity increased and dopamine amount decreased in the DMT group. These results suggest that DMT may support the sympathetic nervous system. To summarize, DMT could be effective in beneficially modulating concentrations of serotonin and dopamine, furthermore in improving psychological distress in youth with mild depression [24]. 


\section{Conduct disorder and mood problems}

A retrospective study conducted in the United States, noticed that DMT impacts moods of adolescents despite gender of diagnosis [25].

\section{Stress management}

A randomized controlled trial15 compared the result of a DMT group intervention on stress management improvement and stress-relief with a wait-listed control group (WG). Results indicate that DMT group treatment is more effective to improve stress management and reduce psychological distress than no treatment, and DMT effects last over time[26].Lidovitch researched and reported on the effectiveness of dance/movement therapy and other mind/body methods in reducing symptoms of anxiety. She examines the literature relevant to this topic and limits the study to include the body/mind approaches of imagery, relaxation, breathing techniques, and DMT. According to her summary, the literature she found supports the notion that DMT and mind/body methods manage anxiety symptoms effectively [49].

\section{CONCEPTUALIZING DANCE/MOVEMENT THERAPY AS MINDFULNESS SKILL}

The building of this research emerged out from the requirement to identify a way to psychologically and somatically describe the deeply personal nature of meditation, as well as determine if participating in guided meditation increased body awareness and ease connecting with the body. Although meditation is traditionally viewed as rooted primarily in cognition, recently, some practitioners have used it to increase focus on a body level as well. Gunaratana (2011) stated: The body alone are able to do nothing for itself; it is like a log not able to move or do anything by itself except become the subject of impermanence, decay, and death. The mind is able to do nothing without the support of the body. Once we mindfully watch both mind and body, we can easily realize how many wonderful things they do together [49].Mindfulness-Based Stress Reduction (MBSR), produced by Jon Kabat -Zinn, has several methods for utilizing mindfulness to reduce long-term stress, including the body scan, a way for focusing meditative attention on specific fields of the body. This treatment program also uses Hatha yoga, sitting meditation and coping skill development with supporting the mindfulness approach [55]. Mindfulness-Based Relapse Prevention (MBRP) can be another program that stresses the cognitive processes explored using mindfulness meditation, the secular edition of Buddhistbased Vipassana meditation, to control craving states and related stress during addiction treatment. Witkiewitz et al. (2005) stated "Mindfulness meditation may disrupt this strategy [the system of the craving response relative to the environment] by supplying heightened awareness and acceptance of the original craving response; without judging, analyzing or reacting” (p. 219). With meditation and the understanding of mindfulness becoming increasingly prevalent in mental well-being treatment, including addiction treatment models, dance/movement practitioners would profit from acknowledging the similarities among the DMT and mindfulness meditation. As discussed above earlier, present moment awareness is a vital to mindfulness. DMT being a therapeutic modality also lives in the present. Movement happens in the now and focusing focus to present-time produces mindfulness. Fundamentally, DMT is a mindful 


\section{Review on Theorizing Yoga and Dance/Movement Therapy as a Mindfulness Skill}

practice. The impact of preventing relapse may, partly, lie in the skill of present moment awareness which helps to detect maladaptive behaviors as they're occurring or about to occur therefore decreasing the likelihood they are going to be repeated going forward. If behaviors are recognized, they might be changed. Without this awareness, the previous continues to intrude itself upon the present all through the recovery process. As we said in Kabat-Zinn (2005), "Mindfulness is more than a meditation practice which could have profound medical and psychological benefits; it is also a way of life that reveals the gentle and loving wholeness that lies at the heart of our being, even within times of great pain and suffering" [56]. The concentration of DMT would be to illuminate the strengths of each one part of an individualmind, body, and spirit- to form a holistic method of healing. It is the opinion of this researcher that these kinds of two practices, mindfulness meditation, and DMT, complement each other in purpose and practice. Thus, they can include safe and nurturing environment from which those in recovery from addiction can start to reacquaint themselves with the most important relationship in their lives---the relationship with self [9].

\section{CONCLUSION}

The intention of this research would be to look into the developing number of therapists educated in each of dance/movement therapy (DMT) and yoga and also to give information regarding the combination of DMT and yoga and how this might influence their mindfulness practices. The literature review presented a summary of mind-body therapies plus the passion developing in this matter and also qualifications information on yoga and DMT, an overview of yoga applied in clinical situations along with its effects when utilized such as a mental health therapy, and more than that an overview of DMT principles and techniques. Yoga and dance movement therapy can be quite complementary activities for clinician's presently training mindfulness. Theorizing applies or being mindfulness skill might turn out to be more engrossing activities for patient populations whom practice the breathing and paying attention to specified by mindfulness but might typically not enjoy involved within the classic mindfulness techniques or courses. Definitely, the get started on of yoga or DMT about alike clinician mindfulness exercising and training could possibly be an alternative choice to the ways currently popularized, to know the movement united with breathing in yoga would be able to provide participants a feeling of really being dynamic, effortlessly drawing their mind free from their thoughts and feelings. This conception of quieting the mind by using body movement is in accordance with how yoga principles have been pointed out previously within this paper. Clinicians might take benefit from this modern mindfulness ability to obtain the advantage of mindfulness more useful to their patients. Moreover, some issues of setting out mindful movement for clinicians are present for guide practice; various yoga routines are available, the study is needed to completely conceptualize the usage of yoga and DMT in future guidelines of mindfulness apply and certainly revealing a yoga routine that is undoubtedly sufficient for lead practice. 


\section{REFERENCES}

[1] F. Röhricht, "Embodied cognition and body psychotherapy: The construction of new therapeutic environments," Sensoria A J. ..., pp. 11-20, 2014.

[2] L. O. Fjorback, "Mindfulness and bodily distress.,” Dan. Med. J., vol. 59, no. 11, pp. 118, 2012.

[3] E. D. Milleson, “The Use of Mindful Awareness Practices in the Classroom,” 2009.

[4] M. Manning, "Awareness Perception Presence : Inquiring into forming a body of work," no. April, 2009.

[5] T. Gordon, “Theorizing Yoga as a Mindfulness Skill,” Procedia - Soc. Behav. Sci., vol. 84, pp. 1224-1227, 2013.

[6] J. Kabat-Zinn, “Mindful Yoga 2,” 2002.

[7] L. Meeks, "Understanding the Personal Meaning of the Metaphor, 'Body as Home' for Application in Dance/Movement Therapy,” no. September, 2012.

[8] J. Fran, D. Movement, and T. a Healing, Dance/Movement Therapy. A Healing Art., no. 2. 1988.

[9] M. a Sanchez, "Mindful Bodies : The Use of Guided Meditation with Dance / Movement Therapy in Addiction Treatment," Danc. Ther. Couns. Theses, 2012.

[10] A. Borskey, "Interactions of Dual Training and Practice in Dance/Movement Therapy and Yoga:,” no. August, 2007.

[11] Y. Meenakshi and D. Bhavanani, "THE HISTORY OF YOGA FROM ANCIENT TO MODERN TIMES,” pp. 1-21.

[12] K. Yoga, J. Yoga, B. Yoga, and R. Yoga, "Yoga - Wikipedia, the free encyclopedia Page 1 of 8,” pp. 1-8, 2008.

[13] S. S. Sivananda, Practice of Karma Yoga. 1995.

[14] “The History of Yoga: Part 1|3FC,” p. 9810.

[15] K. Baier, “Modern Yoga Research: Insights and Questions,” Univ. Vienna, vol. 5, no. 5, pp. 1-20, 2011.

[16] J. Pilates and T. Pilates, "Pilates and yoga - health benefits Pilates explained,” pp. 1-5.

[17] T. Field, "Yoga clinical research review," Complement. Ther. Clin. Pract., vol. 17, no. 1, pp. 1-8, 2011.

[18] S. G. Hofmann, A. T. Sawyer, A. a. Witt, and D. Oh, "The effect of mindfulness-based therapy on anxiety and depression: A meta-analytic review.,” J. Consult. Clin. Psychol., vol. 78, no. 2, pp. 169-183, 2010.

[19] N. Population, “COMPARATIVE STUDY ON LUNG VOLUMES AND CAPACITIES,” vol. 4, no. 8, pp. 2087-2094, 2015.

[20] S. Subrahmanyam, “The science of yoga therapy,” Yoga Aware., vol. 4, pp. 37-39, 1980.

[21] K. B. Smith and C. F. Pukall, "An evidence-based review of yoga as a complementary intervention for patients with cancer,” Psychooncology., vol. 18, no. 5, pp. 465-475, 2009.

[22] J. a Raub, "Psychophysiologic effects of Hatha Yoga on musculoskeletal and cardiopulmonary function: a literature review.," J. Altern. Complement. Med., vol. 8, no. 6, pp. 797-812, 2002. 


\section{Review on Theorizing Yoga and Dance/Movement Therapy as a Mindfulness Skill}

[23] S.-L. Keng, M. J. Smoski, and C. J. Robins, "Effects of mindfulness on psychological health: a review of empirical studies.,” Clin. Psychol. Rev., vol. 31, no. 6, pp. 1041-1056, 2011.

[24] J. Duhovska and M. Paipare, "EFFECTIVENESS OF DANCE MOVEMENT THERAPY - a review of studies,” pp. 1-14.

[25] A. N. Anderson, H. Kennedy, P. DeWitt, E. Anderson, and M. Z. Wamboldt, "Dance/movement therapy impacts mood states of adolescents in a psychiatric hospital," Arts Psychother., vol. 41, no. 3, pp. 257-262, 2014.

[26] I. Bräuninger, "Dance movement therapy group intervention in stress treatment: A randomized controlled trial (RCT),” Arts Psychother., vol. 39, no. 5, pp. 443-450, 2012.

[27] R. a. Baer, "Mindfulness training as a clinical intervention: A conceptual and empirical review,” Clin. Psychol. Sci. Pract., vol. 10, no. 2, pp. 125-143, 2003.

[28] Helan' and EWahbeh, "Mindfulness Meditation for Posttraumatic Stress Disorder."

[29] L. Dimeff and M. M. Linehan, "Dialectical Behavior Therapy in a Nutshell," Calif. Psychol., pp. 1-3, 2001.

[30] S. C. Hayes, S. C. Hayes, J. B. Luoma, J. B. Luoma, F. W. Bond, F. W. Bond, A. Masuda, A. Masuda, J. Lillis, and J. Lillis, “Acceptance and commitment therapy: model, processes and outcomes.,” Behav. Res. Ther., vol. 44, no. 1, pp. 1-25, 2006.

[31] M. E. Larimer, R. S. Palmer, and G. A. Marlatt, "Relapse prevention: An overview of Marlatt’s Cognitive-Cehavioral Model.,” Alcohol Res. Heal., vol. 23, no. 2, pp. 151-60, 1999.

[32] J. L. Kristeller and R. Q. Wolever, "Mindfulness-based eating awareness training for treating binge eating disorder: the conceptual foundation.," Eat. Disord., vol. 19, no. 1, pp. 49-61, 2011.

[33] N. Bardacke and N. Bardacke, "Mindfulness-Based Childbirth and Parenting ( MBCP ): A health promotion model of childbirth education ?," vol. 2, no. 2, pp. 34-37, 1989.

[34] M. B. Ospina, K. Bond, M. Karkhaneh, L. Tjosvold, B. Vandermeer, Y. Liang, L. Bialy, N. Hooton, N. Buscemi, D. M. Dryden, and T. P. Klassen, "Meditation practices for health: state of the research.”, Evid. Rep. Technol. Assess. (Full. Rep)., no. 155, pp. 1-263, 2007.

[35] "Yoga sū traS -."

[36] B. Sistig, I. Lambrecht, and S. H. Friedman, "Journey back into body and soul - An exploration of mindful yoga with psychosis,” Psychosis, pp. 1-12, 2014.

[37] J. K. Crawford, G. Shrestha, and L. G. Hill, "Preliminary Evidence for Infusing Mindfulness , Yoga and Parenting Education Training on the Resilience-building Capacity for Incarcerated Fathers,” vol. 13, no. 2, pp. 1-14, 2015.

[38] S. Richeson, "Helping To Heal Through Yoga: Exploring Yoga As An Adjunctive Therapy Tool For Adult Survivors Of Childhood Sexual Abuse,” J. Chem. Inf. Model., vol. 53, pp. 1689-1699, 2013.

[39] S. Khanna and J. M. Greeson, "A narrative review of yoga and mindfulness as complementary therapies for addiction,” Complement. Ther. Med., vol. 21, no. 3, pp. 244- 
252, 2013.

[40] Ralph La Forge Duke, "Mindful Exercise in Health and Disease,” no. February, 2012.

[41] M. Kub, Chrys Tim McCall, "Yoga As Medicine,” pp. 1-9, 1970.

[42] A. L. Forfylow, "Integrating yoga with psychotherapy: A complimentary treatment for anxiety and depression,” Can. J. Couns. Psychother., vol. 45, no. 2, pp. 132-150, 2011.

[43] B. Sistig, S. H. Friedman, B. McKenna, and N. S. Consedine, "Mindful yoga as an adjunct treatment for forensic inpatients: a preliminary evaluation," J. Forens. Psychiatry Psychol., pp. 1-23, 2015.

[44] S. G. Hofmann, A. T. Sawyer, A. a Witt, and D. Oh, "The effect of mindfulness-based therapy on anxiety and depression: A meta-analytic review.," J. Consult. Clin. Psychol., vol. 78, no. 2, pp. 169-183, 2010.

[45] J. Carmody and R. a Baer, "Relationships between mindfulness practice and levels of mindfulness, medical and psychological symptoms and well-being in a mindfulness-based stress reduction program.," J. Behav. Med., vol. 31, no. 1, pp. 23-33, 2008.

[46] Hana Azmi, “DYNAMIC MEDITATION IN SPORTS DANCES,” pp. 46-50, 2013.

[47] Sherry W. Goodill, "The Evudence Base for Dance/Movement Therapy in Mental Health,Moving the Body of Knowledge," 2004.

[48] peggy Hackney, "making connection chap 6 ,Total Body integration Through Bartenieff Fundamentals.”.

[49] Venerable H. Gunaratana Mahathera, Mindfulness In Plain English By. 2003.

[50] peggy Hackney, Making Connections Total Body Integration Through Bartenieff Fundamentals, vol. 53, no. 9. 2013.

[51] K. Penfield and J. K. Steel, "Application of Laban Movement Analysis To a Movement for Actors Training Program,” pp. 1-30, 2005.

[52] R. M. Krauss and C.-Y. Chiu, "Language and social behavior," Handb. Soc. Psychol. Vols. 12 (4th ed.)., vol. 2, pp. 41-88, 1998.

[53] D. M. Therapy, P. Volume, M. R. Ba, K. G. Low, P. Vol, M. R. Ba, K. G. Lowarts, P. Vol, and T. Fuchs, "Joraschky P, Lausberg H, Pöhlmann K (Hrsg) (2008) Körperorientierte Diagnostik und Psychotherapie bei Essstörungen,” Psychotherapeut, vol. 54, no. 6, pp. 500-502, 2009.

[54] M. Punkanen, S. Saarikallio, and G. Luck, "Emotions in motion: Short-term group form Dance/Movement Therapy in the treatment of depression: A pilot study," Arts Psychother., vol. 41, no. 5, pp. 493-497, 2014.

[55] A. M. . W. Witkiewitz, Katie .G, "Mindfulness-Based Relapse Prevention for Alcohol and Substance Use Disorders.”.

[56] N. E. Dirubbo, "Full Catastrophe Living," The Nurse Practitioner, vol. 17, no. 2. p. 78, 1992. 